Proceedings of the International Scientific Conference. Volume VII, May $22^{\text {th }}-23^{\text {th }}, 2020.34-42$

\title{
EXPRESSIVE THERAPIES CONTINUUM-INFORMED EVALUATION OF THREE RESOURCE-ORIENTED RECEPTIVE AND ACTIVE MUSIC THERAPY TECHNIQUES IN CANCER PATIENTS IN PSYCHOSOCIAL REHABILITATION PROGRAMME
}

\author{
Jana Duhovska \\ Rīga Stradiņš University, Faculty of Rehabilitation. Psychosocial support centre of Oncology \\ Centre of Latvia, Latvia \\ Inga Millere \\ Rīga Stradiņš University, Faculty of Public Health and Social Welfare, Latvia
}

\begin{abstract}
Expressive Therapies Continuum (ETC), a model posed by Lusebrink and widely used in arts therapies, stipulates that human being is perceiving the world and processing the information in three modes - motion (kinesthetic-sensory perception), emotion (perceptualemotional perception) and thought (cognitive-symbolic perception), and that optimally functioning person can freely function in all the modes, can slide between the poles of each of the mode and can integrate the elements from various modes and poles. And vice versa difficulty or inability to function or being stuck in certain modes, can indicate to malfunction and even psychopathology. If that is the case - purposeful integration of various functions by offering expressive activity promoting utilisation of various functions of the ETC, can promote the optimal functioning. In order to find out the capacity of the three resource-based music therapy activities - 1) receptive music therapy activity, 2) semi-structured musical improvisation, 3) song-writing activity - to stimulate the utilisation of specific levels and polarities of the ETC, participants ( $n=24$ cancer patients participating in the psychosocial rehabilitation programme) were asked to assess the elements of the ETC they applied while executing each of the activities. Results of the study show that during the receptive music therapy activity participants mostly used the affective, symbolic and sensory function, during the song-writing activity the mostly used all ETC functions except for sensory, but musical improvisation provoked application of all the ETC functions, and therefore turned out as ultimate activity, capable of integrating all the modes of perception and information processing.
\end{abstract}

Keywords: Expressive Therapies Continuum; music therapy, cancer patients.

\section{Introduction}

Objective of this research, being part of the doctoral thesis by Jana Duhovska, is to provide analysis of the three resource-oriented music therapy 
techniques - receptive music therapy activity with imagery, semi-structured musical improvisation and a "new lyrics to the old song" technique - to identify the potential of each of the above mentioned for stimulating the artistic expression of the individual at the particular, or various, levels and their polarities of the Expressive Therapies Continuum (ECT) - the theoretical framework that posits that expression and the application of media and techniques in arts therapies, including music therapy, can be seen as taking place on either of the four different levels: kinesthetic/sensory, perceptual/affective, cognitive/symbolic, as well as creative level or vertical axis intersecting the horizontal levels and possibly presenting at any level or representing the integration of functioning from all levels (Lusebrink, 1990). According to the Lusebrink (1990), optimally functioning individual can freely function in all the levels, is able to move between the levels and slide between the poles of a specific level and has a capability to integrate the elements from various levels. And vice versa - difficulty or inability to function in certain levels or being stuck in certain levels or extreme polarities of any level, can indicate to malfunction and even psychopathology. If that is the case - purposeful integration of various functions by offering expressive (here - music-based) activity promoting utilisation of various functions of the ETC, can promote the optimal functioning.

This leads to the goal of the research - amongst the three mentioned, to identify the music therapy technique with the largest potential for stimulating and integrating the various levels and poles of the ETC to further the optimal or multifaceted functioning of the individual, in this case - breast cancer patient undergoing a psychosocial rehabilitation programme.

\section{Literature review}

The Expressive Therapies Continuum (ETC) was conceptualized in reference to visual expression and it is based on the ideas of art educator Victor Lowenfield, cognitive psychologist Jerome Bruner, investigator of imagery in psychiatry Mardi Horowitz, neuroscientist Joaquin Fuster as well as several pioneers of the art therapy (Hinz, 2009 as cited in Mārtinsone et al., 2013). It provides a framework how individuals interact with experiential and creative activities and offers a hierarchy of information processing and creative expression, ranging from simple sensory and kinesthetic experiences to complex symbolic expression.

ETC (Figure 1) is composed of four levels that encompass six components on three levels: kinesthetic-sensory, perceptual-affective and cognitive-symbolic, and the creative fourth level that crosses these horizontal levels perpendicularly. Each level is described as a continuum having two opposite poles, except for intertwining creative level, which is considered as the synthesis or whole-brain 
level (Fernandez et al., 2014) and represents the integration of the functioning from all levels.

Three components also form a developmental hierarchy wherein the individual usually moves from the kinesthetic to the creative level to support the idea of integration as wellness. The three levels are regarded as different from each other, yet they form interconnected systems, and the expression on a particular level of the ETC incorporates the characteristics of a system at a lower level (Lusebrink, 1990).

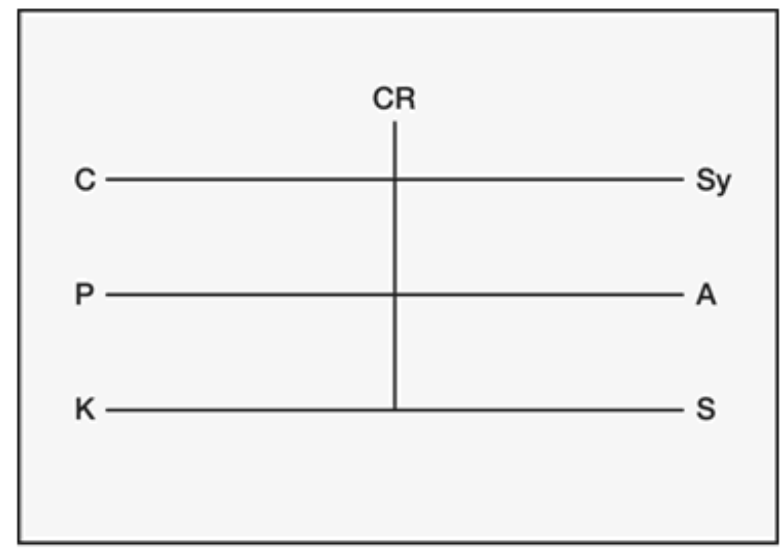

Figure 1 Schematic Representation of the Expressive Therapies Continuum (K/S - Kinesthetic/Sensory, P/A - Perceptual/Affective, C/Sy - Cognitive/Symbolic) (Lusebrink, 1990).

According to Lusebrink, the sequence of the first three levels reflect mental and graphical development in progression from simple to more complex levels of information processing as person is developing through life. The kinesthetic/sensory level is related to the preverbal experience in toddler age where gathering of information does not require words. Perceptual/affective level corresponds to school age children and formal and affective aspects of information processing. The cognitive/symbolic level, on its turn, takes place starting from adolescence, and operating within this level requires planning and complex cognitive action, but the symbolic component helps to connect to inner experiences (Hinz, 2009). As stated before, expression on a particular level of the ETC incorporates the characteristics of a system at a lower level, hence - optimal and uninterrupted development may result in an individual being able to freely utilize of all the levels and poles of the ETC, and vice versa, and in the case of latter, ETC can be applied both for assessment and therapy planning instrument as the criteria provided within the framework provide a rather clear information to identify:

1) the predominance of one or more levels of ETC, therefore revealing the individual's strengths (or lack of difficulty, and of pathology) that can 
serve as an entry point or the secure base to start the therapy from or to return to when processes become too challenging,

2) the missing levels or poles, therefore revealing the individual's deficits that could or should be elaborated during the therapeutic process to attain more optimal functioning.

As to the planning of the therapy process, Lusebrink (20014, 2010) points out that, depending on the needs and pathology of the individual, treatment can include either stepwise bottom-up or top-down transitions between the ETC levels or horizontal transformations with each level, and, to attain the optimal functioning characterized by flexible and versatile activity, purposeful integration of various ETC functions can be successfully organized via artistic activities, e.g. techniques based on music - be it listening, free play or structured activity.

Nevertheless the fact that ECT was originally designed and described within the visually-plastic art (therapy) setting, the application of the model - both assessment-wise as well as for the purposes of planning of the therapy - can take in other modalities of art, including music (Lusebrink, 1992). According to Lusebrink and authors that have further explored application of the ETC to music therapy (Duhovska, Lusebrink, \& Mārtinsone, 2018), in music therapy expression of creating sounds by beating various objects and instruments such as drums occurs in kinesthetic level. Auditory as well as tactile stimulation and sensory responses to sounds and/or playing itself or singing occurs at sensory level. The temporal sequence of music organization contributes the exposure of perceptive level, while expression of senses and mood with sounds emphasizes efficacy at affective level. Cognitive level draws attention to the structure of music, as well as to organized musical group activities whereas on the symbolic level attention is focused to the personal symbolic identification with music as well as improvisation on memories, images and emotional states (Lusebrink, 1992; Duhovska, Lusebrink, \& Mārtinsone, 2018). For detailed information about each of the levels and their specific traits in music therapy see Table 1.

To summarize the contents of the chapter, ETC stipulates that human being is perceiving the world and processing the information through seven functions: kinesthetic/sensory, perceptive/affective, cognitive/symbolic, and creativity, and optimally functioning person can utilize all these aspects. Applied during assessment, ETC framework helps to identify the missing levels or poles, therefore revealing the individual's deficits that could or should be elaborated during the therapeutic process to attain more optimal functioning. Artistic activities, here - music-based activities - provide grounds for purposeful integration of various ETC functions to be developed according to the needs of the individual. 
SOCIETY. INTEGRATION. EDUCATION

Proceedings of the International Scientific Conference. Volume VII, May $22^{\text {th }}-23^{\text {th }}, 2020.34-42$

Table 1 Overview of the ETC levels

(summarized from Duhovska, Lusebrink, \& Mārtinsone, 2018)

\begin{tabular}{|c|c|c|}
\hline $\begin{array}{l}\text { CO > Cognitive: reasoning, } \\
\text { planning, systematizing, verbalizing, } \\
\text { consecutive operations. } \\
\text { In music: complex activities - } \\
\text { coordinated, planned group work, } \\
\text { song writing. } \\
\text { Pathology: thematic or conceptual } \\
\text { disintegration and inconsistency, } \\
\text { chaos in thinking. } \\
\text { Keywords: logical, categorizing. }\end{array}$ & 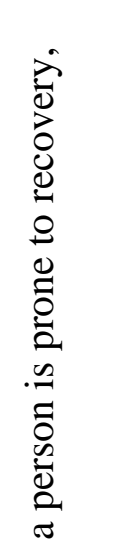 & $\begin{array}{l}\text { Sy > Symbolic: intuition, abstract and } \\
\text { symbolic thinking, images, metaphors, } \\
\text { intuitive conceptualization. } \\
\text { In music: free improvisation on a topic, } \\
\text { using existing images or creating them } \\
\text { as a result of improvisation } \\
\text { Pathology: excessive focus on } \\
\text { symbolism, giving symbolic meaning } \\
\text { to each event and element. } \\
\text { Keywords: intuition, autobiographical } \\
\text { sources, identification. }\end{array}$ \\
\hline $\begin{array}{l}\text { P > Perceptive: structure, shape, } \\
\text { sequence, background and } \\
\text { foreground, rhythm, recurrence, } \\
\text { concentration towards result. } \\
\text { In music: completeness of motifs, } \\
\text { melodies, distinction between } \\
\text { background and soloist. } \\
\text { Pathology: excessively rigid forms, } \\
\text { repetition of forms, excessive detail. } \\
\text { Keywords: control, regulation. }\end{array}$ & 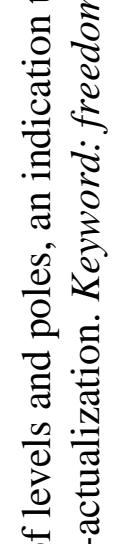 & $\begin{array}{l}\text { A > Affective: exploration and release } \\
\text { of emotions, loss of control, } \\
\text { concentration towards the process. } \\
\text { In music: use of voice or instrument to } \\
\text { express emotions. } \\
\text { Pathology: excessive emotionality, } \\
\text { uncontrolled expression and inability } \\
\text { for any structure or melody; chaos, } \\
\text { also - inconsistency between the } \\
\text { content and expression } \\
\text { Keywords: being carried away }\end{array}$ \\
\hline $\begin{array}{l}\text { K > Kynesthetic: action, tension, } \\
\text { tempo, energy, physical release, } \\
\text { effort, simple movements. } \\
\text { In music: utilisation of instrument or } \\
\text { voice in a "physical» way - singing } \\
\text { with force/pressure or as whispering, } \\
\text { playing with force or gently. } \\
\text { Pathology: apparent lack of energy or } \\
\text { overly excited, agitated activity that } \\
\text { results in damage to art materials } \\
\text { (incl. musical instruments) or the } \\
\text { personal boundaries of others. } \\
\text { Keywords: release of energy, } \\
\text { physicality. }\end{array}$ & 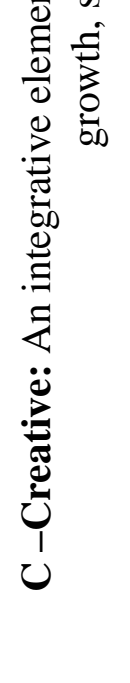 & $\begin{array}{l}\text { S > Sensory: sensations - in fingers } \\
\text { and palms while touching objects, } \\
\text { smell, hearing. Artistic expression as } \\
\text { getting ones' attention towards bodily } \\
\text { sensations. } \\
\text { In music: hearing, sensing the air } \\
\text { traveling via voice cords, different } \\
\text { sensations while touching instrument } \\
\text { with palm, stick, fingertips } \\
\text { Pathology: excessive focus on the } \\
\text { senses and prolonged, deep immersion } \\
\text { in sensory research } \\
\text { Keywords: sensing here and now. }\end{array}$ \\
\hline
\end{tabular}




\section{Methodology}

Breast cancer patients $(n=24$, interval 47-61, Me $=60)$, working in four groups, were receiving music therapy during a psychosocial rehabilitation programme that comprised complex approach, including sports, education and psychosocial support. Music therapy part of the programme, being part of the psychosocial support module, consisted of four 90-minute sessions, and was designed to address the state anxiety, emotion regulation and overall psychological quality of life issues for participants to be able to return to employment and to gain active position after the treatment.

Amongst the others, participants experienced three music based activities, that were later analysed in relation to the research questions:

1) receptive music therapy activity with imagery - listening to light, relaxing music with nature sounds and being encouraged to daydream, visualize,

2) semi-structured musical improvisation - playing a group improvisation with semi-fixed contents as group was instructed about a specific story - imaginary material derived during the 1) activity - to musically improvise about,

3) "new lyrics to the old song" technique - creating new lyrics to a wellknown folk melody, the new lyrics were instructed to be covering the collaboration experience in group.

In order to identify the music therapy technique with the largest potential for stimulating and integrating the various levels and poles of the ETC, participants were asked to rate the top three functions of the ETC that were utilized during each of the activities, and to allot:

- 3 points to the function that was utilized most frequently and intensely,

- 2 points to the function that was used quite prominently,

- 1 point to the function that was less, but definitely present.

The rating process was organized in two rounds:

1) at first, the participants were doing their individual work - they received worksheets with an ETC scheme and notes explaining the contents of each of the ETC levels and poles in plain language. Then, utilizing postit notes to rate the top three functions, participants did their rating individually,

2) after that, participants approached the larger poster with an ETC scheme and copied their individual scores to the joint poster.

Researcher then counted the points allotted to each of the function for each of activity, summarized the results and finished with a group discussion to provide 
SOCIETY. INTEGRATION. EDUCATION

Proceedings of the International Scientific Conference. Volume VII, May $22^{\text {th }}-23^{\text {th }}, 2020.34-42$

an opportunity not only to score, but also to (qualitatively) describe the specific experience.

\section{Research results and Discussion}

During the receptive music therapy activity with imagery - listening to light, relaxing music with nature sounds and being encouraged to daydream and visualize, top functions of the ETC utilized by participants were affective and symbolic (as predicted), and also sensory function, describing the experience of visualisation and relaxation as rather bodily, and not only in terms of relaxing ones' body, but also in experience that might be considered as a result of integration of sensory, affective and symbolic function, such as: "feeling of warmth from outside [like lying in the sun]", "feeling my skin glowing”, "sensing the chill of the wind and leaning shadow of trees", "feeling like melting with the soil”, "extreme support and grounding, getting strength from the living world".

Table 2 Top 3 ETC functions for receptive music therapy activity with imagery

\begin{tabular}{|c|c|c|}
\hline $\mathrm{CO}>$ Cognitive $=20$ POINTS $(4)$ & \multirow{3}{*}{ 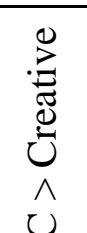 } & Sy $>$ Symbolic $=32$ POINTS $(3)$ \\
\hline $\mathrm{P}>$ Perceptive & & A $>$ Affective $=54$ POINTS (1) \\
\hline K > Kynesthetic & & $\mathrm{S}>$ Sensory $=38$ POINTS (2) \\
\hline
\end{tabular}

Looking at the semi-structured musical improvisation - there were all the six elements of the ETC utilized within this activity (Table 3), the most prominent of them being affective, symbolic and perceptive functions, but also the other elements in somewhat notable proportion. This technique was described by participants as "magical" and "life affirming", and participants demonstrated ability to rich symbolic functioning, e.g. referring to percussion folk instrument trejdeksnis as strong, stately lady, kokle as dawn, zvongo as space and universe, conga as war and conflict, wind chimes as light wind, and so on.

Participants also referred to the perceptive function - need for the start and end for the improvisation, need for distinguishing between melody and background as well as need to be present, to fit in the overall story, also - fear of the [musical] chaos and cacophony.

If compared with the other activities analysed during this research, this activity demonstrated itself in the most powerful manner, and part of the success could also be due to the link with the listening activity: participants played the story owned by themselves, and could continue journey that was started during the receptive music therapy part. As well, receptive music therapy task had 
provided great grounds for further grow - with the sense of "feeling powerful and [finally] well in ones' body", it had also promoted the feeling of "strength that is within and can be turned on as soon as it is needed".

Table 3 Top 3 ETC functions for musical improvisation

\begin{tabular}{|c|c|c|}
\hline $\mathrm{CO}>$ Cognitive $=14$ POINTS & \multirow{3}{*}{$\begin{array}{l}\stackrel{\Xi}{\Xi} \\
\stackrel{\Xi}{ } \\
\hat{U} \\
\hat{u}\end{array}$} & Sy $>$ Symbolic $=32$ POINTS (2) \\
\hline $\mathrm{P}>$ Perceptive $=22$ POINTS (3) & & A $>$ Affective $=44$ POINTS (1) \\
\hline $\mathrm{K}>$ Kynesthetic $=16$ POINTS & & $\mathrm{S}>$ Sensory $=16$ POINTS \\
\hline
\end{tabular}

Referring to the "new lyrics to the old song" technique, the participants used all ETC functions except for sensory (Table 4), focusing not only on the cognitive and perceptive functions (as expected), but also on the affective pole, being characterized by themselves as "joy for collaboration, sadness that programme has come to an end, pride for daring to participate, caring about supporting peer ideas”.

Table 4 Top 3 ETC functions for "new lyrics to the old song"

\begin{tabular}{|c|c|c|}
\hline $\mathrm{CO}>$ Cognitive $=60(1)$ & \multirow{3}{*}{$\begin{array}{l}\stackrel{\circlearrowright}{0} \\
\stackrel{0}{0} \\
\stackrel{U}{U} \\
\wedge\end{array}$} & Sy $>$ Symbolic $=12$ \\
\hline P > Perceptive = 39 (2) & & A $>$ Affective $=29$ (3) \\
\hline $\mathrm{K}>$ Kynesthetic $=4$ & & S > Sensory \\
\hline
\end{tabular}

\section{Conclusions}

The Affective and Symbolic component has been present to a significant extent in the realization of each of the activities, but in general it is possible to identify target areas that are more specific to each activity:

1. Receptive music therapy technique can be targeted towards activisation of images, emotions, senses (symbolic, affective, sensory),

2. Musical improvisation: ultimate, the most potent activity with the potential to stimulate all functions of the ETC and promote integrated functioning, if linked with personal contents or source,

3. "New lyrics to the old song" technique: reasoning, systematizing, putting into order (cognitive, perceptive, affective). 


\section{References}

Duhovska, J., Lusebrink, V.B., \& Mārtinsone, K. (2018). Assessment and therapeutic application of the Expressive Therapies Continuum in music therapy: The case of Anna with cancer-related depression. In A. Zubala, \& V. Karkou. Arts therapies in the treatment of depression. (pp. 241-255). New York: Routledge.

Fernandez, K.T., Serrano, K.C.M., \& Tongson, C.C. (2014). An Intervention in Treating Selective Mutism Using the Expressive Therapies Continuum Framework, Journal of Creativity in Mental Health, 9-1.

Hinz, L.D. (2009). Expressive therapies continuum: A framework for using art in therapy. New York: Routledge/Taylor \& Francis Group.

Lusebrink, V.B. (1990). Imagery and visual expression in therapy. New York: Plenum Press.

Lusebrink, V.B. (1992). A systems-oriented approach to the expressive therapies: The Expressive Therapies Continuum. The Arts in Psychotherapy, 18(5), 395-403.

Lusebrink, V.B. (2004). Art therapy and the brain: An attempt to understand the underlying processes of art expression in therapy. Art Therapy: Journal of the American Art Therapy Association, 21(3), 125-135.

Lusebrink, V.B. (2010). Assessment and therapeutic application of the expressive therapies continuum: Implications for brain structures and functions. Art Therapy, 27(4), 168-177.

Mārtinsone, K., Šilova, I., Lusebrink, V.B., \& Veide-Nedviga, L. (2013). The expressive therapies continuum: an integrative systemic approach to visual expression and its historical background. Медицинская психология в России, 22(5), 1 - 30. 